\title{
Certificate of Need: Legal nightmare in the making?
}

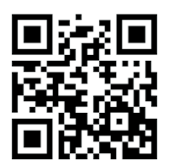

Telling healthcare providers where they may or may not practice, based purely on creating an equitable spread of healthcare services across the country (i.e. the newly promulgated Certificate of Need (CoN) law), may prove a legal nightmare, ultimately undermining healthcare delivery.

In spite - or perhaps because - of this, three of the country's top doctor bodies have adopted a conciliatory approach, appealing to government to embrace their expertise and coalface experience in helping more South Africans access quality healthcare after the sudden promulgation of the long-dormant law. Regulations have yet to be drawn up.

The CoN, if passed in its current form, will have far-reaching unintended consequences for the private sector, and the doctor bodies are convinced that this could undermine its commendable intentions. While fully behind the government's aim to improve access to healthcare, particularly in underserved areas, they believe that as it currently stands it is a clumsy legal instrument that could so disadvantage healthcare providers and patients as to worsen rather than improve access to services. The South African Medical Association (SAMA), the country's largest representative doctor body, the South African Dental Association (SADA), its equivalent for dentists, and the South African Private Practitioners Forum (SAPPF), the largest private specialist body, have banded together to form a united front, urgently engaging government to help create a more universally beneficial outcome. Other major players such as the Hospital Association of South Africa (HASA) are opting for an even more cautious approach, conducting rapid research in all relevant fields before deciding whether to join the 'diplomatic doctor' initiative. Top Izindaba sources confided that the sudden promulgation of the law, put on ice in the Mbeki era after it ran into a firestorm of controversy, has caught most in the private sector by total surprise.

Several of the relevant sections of the National Health Act, first drafted in 2003 when relations between most nongovernment healthcare bodies and the Thabo Mbeki government were at an all-time low (over HIV/AIDS), remain unclear. The entire law gives unfettered

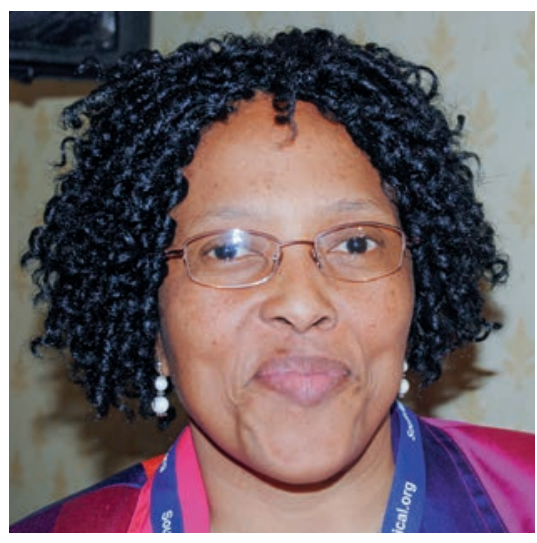

Malebona Precious Matsoso, National DirectorGeneral of Health. Picture: Chris Bateman.

power to the Director-General of Health, currently Malebona Precious Matsoso, to effectively to decide where all healthcare providers, facilities and medical equipment (undefined) may or may not operate or practise. The instrument for this is the $\mathrm{CoN}$ - and all healthcare providers have until 1 April 2016 to apply for it. The regulations, which the doctor bodies want to be intimately involved in drawing up to prevent alarming prohibitive constraints on them and their patients, are to be drafted as part of a 'consultative' process before then. However, the regulations may not conflict with the provisions of the Act, making it unlikely that they will remedy the doctor groupings' fundamental concerns.

\section{What the law says}

According to the law, a $\mathrm{CoN}$ will be required for anyone: (i) establishing, constructing, modifying or acquiring a health establishment or agency; (ii) increasing the number of beds in, or acquiring prescribed health technology at, a health establishment or health agency; (iii) providing 'prescribed' health services; or (iv) continuing to operate a health establishment or health agency after the expiration of 24 months from the date at which the relevant addition to the Act took effect (1 April 2014). The Act also requires the Director-General of Health (or their designate) to apply their minds to a host of requirements before issuing a certificate. These range from consistency of health services development in terms of planning, equitable distribution and rationalisation of services and resources (including existing public and private facilities in an area), and correcting racial, gender, economic and geographical imbalances, to taking into account the demographic and epidemiological characteristics of the population to be served, plus furthering the Employment Equity Act in emerging small, medium and micro-enterprises.

\section{Road to final enactment full of potholes}

Examination of the resuscitated law by the three doctor bodies - and the entire medical fraternity, which is abuzz with anxious debate - reveals that it severely limits not only the rights of healthcare providers but also those of patients in accessing care and medical information; that it could render existing medical businesses worthless; and that it will create a mountain of red tape, with a huge and expensive bureaucracy. Practical administrative issues such as ensuring that locums possess a CoN, selling a practice or taking on partners, and the clashing of the CoN with at least six other existing laws (the Consumer Protection Act, the Promotion of Access to Information Act, the Promotion of Equality and Prevention of Unfair Discrimination Act, the Health Care Professions Act and the Protection of Personal Information Act), pose major problems. Besides this, the CoN conflicts with constitutional provisions protecting freedom of movement and association, which is likely to render the consultative process tricky and longer than the actual law permits.

\section{SAMA's perspective}

Dr Mzukisi Grootboom, Chairperson of SAMA, said that besides the lack of consultation after the nine-year dormancy and its sudden enactment by President Jacob Zuma this April, the CoN could create several perverse outcomes. 'One immediately asks, will it affect only newcomers to the system (as similar laws are widely applied internationally), or those already practising? It's quite clear from the way it's written that everybody practising will have to get a CoN just to justify your existence and where you practice.' (Failure to comply will result in a fine or five years' imprisonment, or both.) Grootboom said that among the potential unintended consequences are the 
closing down of practices and the denial of healthcare to existing populations.

An examination of the equivalent law introduced in the USA showed that it was used to adjudicate on aspirant healthcare facilities in order to avoid over-concentration of services and expensive equipment in one area. SAMA was 'totally behind' improving access to healthcare in underserviced areas in South Africa (SA), but did not believe the $\mathrm{CoN}$ was the only instrument to use. Asked Grootboom: 'Can the CoN be one of the instruments? The answer is theoretically maybe, based purely on whether it's practical. But what remedies are in place to address the host of unintended consequences?' He said that besides anecdotal evidence, there was ample research to show that simple remuneration did not keep healthcare providers in place (government has implemented the Occupation-Specific Dispensation (OSD) and rural allowance incentives). This had emerged from the national health department's own White Paper on Human Resources for Healthcare. The experience of SAMA's public sector members was that 'the terrain out there is extremely unsupportive to doctors'. Besides drug stock-outs, lack of instruments and supervision, and the scarcity of subsidised accommodation, most hospitals were run by 'people with no idea about medicine and healthcare delivery. They're only interested in keeping within a budget; service delivery is neither here nor there to them.' Grootboom pleaded with government 'for all of us to sit down and work out what instruments to use to ensure we become responsible to the needs of the population. Things like creating more viable campuses in the more rural provinces and retaining high-level teaching staff ... We need to make sure people have a reason to stay there.' He cited the Thai model, where most training centres are now in underserviced, outlying areas, attracting high-level expertise. He said that government had an unfortunate track record in partnering with doctors to find solutions. 'A lot of us are sensitive to what the ANC and the government are trying to achieve in addressing disparities - and they're bound to make mistakes. So we need to rise above petty squabbles and let them know they have our support - but please involve those of us who deal with patients on a daily basis instead of controlling us from the outside.'

Grootboom said he had spoken to Matsoso, who said the $\mathrm{CoN}$ was needed to empower the new Office of Healthcare Standards, a core component of the incoming National Health Insurance dispensation (i.e.

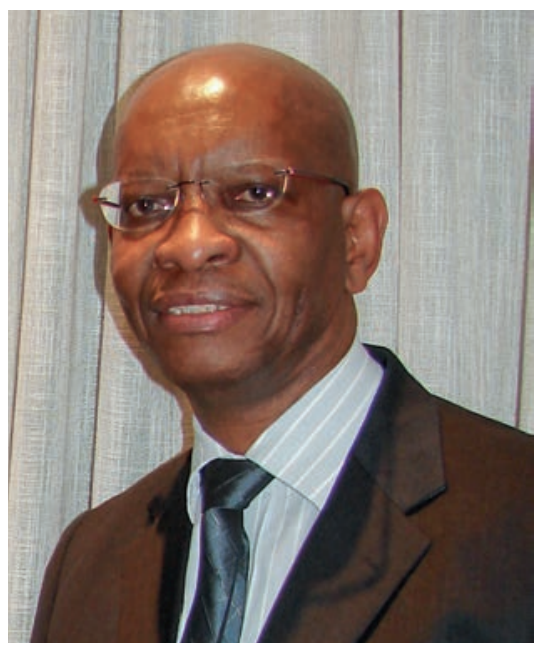

Dr Mzukisi Grootboom, SAMA Chairperson. Picture: Chris Bateman.

universal healthcare access). 'She said that when they [healthcare standards officers] go around checking facilities, they also need to check if they have a certificate to run that particular healthcare facility. Matsoso had conceded to him that there 'might be constitutional problems which need addressing', but whatever reassurances she made, 'what's written [in the new law] is what's written. Top constitutional lawyer in healthcare, Elsabe Klinck, said no standards have been issued for various types of practices in the private sector yet, and the health department must first climb a mountain of administration before these can be promulgated, let alone have the Office of Health Standards Compliance conduct inspections and then go through $\mathrm{CoN}$ applications for thousands of establishments. National health department spokesman Joe Maila reflected Matsoso, saying 'nothing is going to be unilateral' and adding that it would be unconstitutional to force doctors to work in places where they did not want to. He promised that 'nothing will be done without full consultation'. Klinck said that a CoN would be linked to the building in which the professional worked, but Maila could not explain what would happen if a certificate was denied, or how the process would work for specialists who work at three different private hospitals, as is common.

\section{The dentists' view}

Maretha Smit, CEO of SADA, said doctors and dentists cared about South Africans and wanted to partner with government in addressing the principle of universal access to healthcare. However, 'we'd like to ask that this be consistent, constructive and solutionsdriven and to include engagement with the professions. To alienate the professions simply means that government won't be able to reach their target.' She said that on a 'cold reading of the Act we are fundamentally affected - but when you speak to health department representatives they take a much more pragmatic and conciliatory approach, even admitting they don't have the resources to look at every individual practice'.

Smit said the professions were 'crying out for a carrot approach - we're talking about people who went into a certain profession because they care. I get the sense from my members that they really want to make an impact on providing health for as many people as possible.' There appeared to be an official lack of understanding of the difficulties inherent in the practice environment. The over-riding focus for practitioners had become 'how do I survive?' instead of 'how do I care?'. 'If we take the "how do I survive" out of the equation, you'll get a lot more people saying "how do I care?"!' she stressed.

SA's healthcare problems seemed not so much about ideology but execution. 'I'm constantly amazed at the decisions taken without an understanding of the risks attached and a comprehensive analysis of the downstream impact and potential of where things could go wrong.' Smit warned that this could result in a dramatic downturn in people wanting to enter the healthcare professions, with dire national implications.

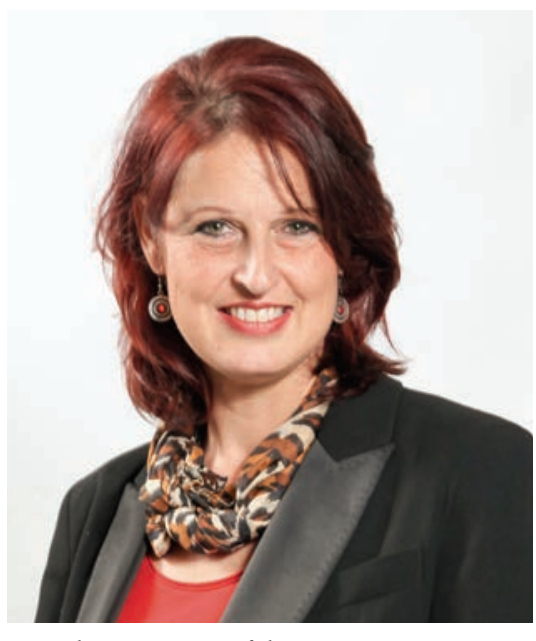

Maretha Smit, CEO of the SADA.

\section{Private doctors' body} speaks

Dr Chris Archer, CEO of the SAPPF, echoed Grootboom, saying that 'we have to look at the Act itself, not the interpretation of the Act by the Director-General'. He also emphasised that the SAPPF was not in opposition to 


\section{Stop Press: Motsoaledi's impromptu response on CoN}

National Minister of Health Dr Aaron Motsoaledi, button-holed briefly by Izindaba as he was leaving a press conference after delivering the closing speech at the 4th SA TB Conference in Durban on 13 June, had this to say about private doctor alarm at the Certificate of Need.

'They're looking at [i.e. the law speaks of] health facilities. When it comes to individuals it will be very difficult to force any doctor to move. There will be a big discussion on this issue; it's not something we're going to apply inhumanely and mechanically. We'll meet doctors to discuss the parameters. I don't understand all the objections - I mean [Netcare] Park Lane Clinic [in Parktown, Johannesburg] has more gynaes than Limpopo and Mpumalanga provinces put together! It will be difficult to force them to move - but should we allow more gynaes to move into that small space called Park Lane? I don't think so!' the government's ultimate objective, but to the methodology used in getting there. As the law stood, it was an experiment in social engineering' that seemed doomed to failure with huge potential for bribery and corruption. Unless there was a pragmatic accommodation of healthcare providers' concerns in the regulations, doctors could end up 'voting with their feet'.

Archer said that in terms of the Act, the CoN definition of a health establishment included established practices. While there was some talk of a grandfather clause, 'what about when I want to retire and sell my practice? If the DG decides there are too many gynaes in my hospital and wants to spread elsewhere, she won't issue a certificate for my practice and I'll have nothing to sell. The same applies to father and son, mother and daughter, coming into a practice.' The concept of a third party determining one's fate 'because they have the power to do so' was 'complete anathema' to the SAPPF. 'Even if they are magnanimous, they still have the power ... and what happens when the DG or the Minister of Health changes?' he asked. He wants the law to be changed to exclude established practitioners, enabling professionals working in a well-served area to sell their practice to a new entrant, who would then have to apply. He also suggested setting a maximum price ceiling on equipment affected by the Act to enable the upgrading of less costly equipment such as ultrasound scanners.

Archer described the CoN promulgation as 'very worrying indeed', but said he took some comfort in the vastly increased accessibility of the Minister of Health and his DG, compared with when the law was first mooted. Casper Venter, Director of the Healthman Consultancy, said the certificates would be an 'administrative nightmare'. 'There are about 70000 dieticians, specialists, GPs, physiotherapists and occupational therapists who would all need certificates to open a new practice in private. The Department is not geared for this kind of [action]. If a doctor is prevented from opening a practice in Sandton, it is not clear if he or she will then work in nearby Alexandra.' Klinck appealed to healthcare professionals not to panic or act prematurely. 'One of the criteria in the Act is the financial viability of a practice, which would mean no one could force a practitioner to start a practice in an area where it would not be financially viable,' she said.

\section{Chris Bateman}

chrisb@hmpg.co.za

S Afr Med J 2014;104(7):459-461.

DOI:10.7196/SAMJ.8550 